\title{
Satisfaction, preference and error occurrence of three dry powder inhalers as assessed by a cohort naïve to inhaler operation
}

This article was published in the following Dove Press journal: International Journal of COPD

\author{
Kwun Nok Mimi Man ${ }^{1, *}$ \\ Zhipeng Tian ${ }^{1, *}$ \\ David Chi-Leung Lam² \\ Jennifer Man Fan Wan ${ }^{3}$ \\ Kian Cheng Tan-Un' \\ 'University of Hong Kong, School \\ of Professional and Continuing \\ Education, Hong Kong SAR, \\ China; ${ }^{2}$ University of Hong Kong, \\ Department of Medicine, Li Ka Shing \\ Faculty of Medicine, Queen Mary \\ Hospital, Hong Kong SAR, China; \\ ${ }^{3}$ University of Hong Kong, School \\ of Biological Sciences, Hong Kong \\ SAR, China \\ *These authors contributed equally \\ to this work
}

Correspondence: Kian Cheng Tan-Un University of Hong Kong, School of Professional and Continuing Education, I3/F, Fortress Tower, 250 King's Road, North Point, Hong Kong SAR, China

$\mathrm{Tel}+8522975588 \mathrm{I}$

Fax +852 27073620

Email kctan@hkuspace.hku.hk
Background: Inhaled medication is central to the treatment of COPD. Various types of inhaler devices, which directly deliver medication to the lung, have been developed. However, patients often exhibit incorrect techniques of inhaler usage. Effectiveness of therapy may be affected by the ease of device usage, size, convenience of use, durability, clarity of instructions and device preferences of patients. This study compares the satisfaction and preference, as well as error occurrence, with the use of Genuair ${ }^{\circledR}$, Ellipta ${ }^{\mathrm{TM}}$ and Breezhaler ${ }^{\mathrm{TM}}$ by healthy subjects in Hong Kong.

Subjects and methods: One hundred and thirty healthy Hong Kong Chinese subjects aged $\geq 40$ years without a previous diagnosis of COPD and asthma and with no experience of using dry powder inhalers (DPIs) were recruited. Subjects learned to use the three DPIs by initially reading the instructions and then observing a demonstration with verbal explanation. The number of errors committed was evaluated. Subjects also completed a questionnaire to indicate their satisfaction and preference.

Results: The satisfaction score of comfort for Breezhaler was significantly higher than that for Ellipta ( $p \leq 0.05$ ), while the satisfaction score on confidence to have inhaled the entire dose was highest for Genuair compared with Ellipta $(p \leq 0.0001)$ or Breezhaler $(p \leq 0.05)$. The overall satisfaction score was significantly higher for Genuair than Ellipta $(p \leq 0.05)$ or Breezhaler ( $p \leq 0.01$ ). After reading the instructions, the highest number of subjects committing one or more critical errors was with Breezhaler (97) followed by Genuair (70) and then Ellipta (33). Demonstration reduced the number of critical errors made by subjects for each DPI to one third or lower.

Conclusion: Breezhaler seemed to be more comfortable and easy to carry, but users made less critical errors when using Ellipta after reading the instructions only. Genuair provided the clearest indication of correct dose preparation and inhalation.

Keywords: chronic obstructive pulmonary disease, inhalation device, Genuair ${ }^{\mathbb{R}}$, Ellipta ${ }^{\mathrm{TM}}$, Breezhaler ${ }^{\mathrm{TM}}$

\section{Introduction}

Inhaled medications, including short-acting and long-acting bronchodilators as well as inhaled corticosteroids, are central to the management of COPD. Various types of inhalers have been developed to enable direct delivery of inhaled medications to the lung, thus minimizing unwanted systemic effects and allowing smaller doses to be used with faster onset of drug action; ${ }^{1-4}$ for instance, the pressurized metered-dose inhalers, soft-mist inhalers, dry powder inhalers (DPIs) and nebulizers. DPIs and soft-mist inhalers represent significant improvements from pressurized metered-dose inhalers, 
as they do not contain propellant gases and importantly are breath-actuated, circumventing the need for coordination of inhaler actuation and inspiration by the patient. ${ }^{3,5,6}$ However, only $40 \%-60 \%$ of COPD patients adhered to their prescribed therapy $^{7}$ and, depending on the types of inhalers, between $4 \%$ and $94 \%$ of patients exhibited incorrect techniques of inhaler device usage. ${ }^{8}$ Although patients claimed that their techniques of inhaler use is adequate, as many as $94 \%$ still committed at least one error when they were asked to demonstrate the correct techniques, ${ }^{9}$ showing the need for patient education and critical assessments on inhaler device usage by health care professionals. Moreover, the risk of COPD increases by 5 -fold for people aged over 65 years as compared to those under 40 years of age. ${ }^{10}$ Elderly patients are more likely to have reduced dexterity and cognitive function, which limit their ability to correctly operate inhalers. Inadequate adherence to prescribed regimens and failure to use the correct technique result in reduced effectiveness of therapy. ${ }^{11,12}$ Factors affecting patient satisfaction and preference of inhalers include ease of use, size, convenience, durability and clarity of instructions. ${ }^{13,14}$

The three most recently launched DPIs for COPD were studied - Genuair ${ }^{\circledR}$ (AstraZeneca, Cambridge, UK), Ellipta ${ }^{\mathrm{TM}}$ (GlaxoSmithKline, Brentford, UK) and Breezhaler ${ }^{\mathrm{TM}}$ (Novartis, Basel, Switzerland). Genuair is a multidose, mediumresistance DPI for the delivery of aclidinium bromide, a longacting muscarinic agonist (LAMA), or aclidinium bromide in combination with formoterol fumarate dihydrate, a longacting beta agonist (LABA). ${ }^{14,15}$ It provides both visual and acoustic feedback to patients to indicate correct inhalation of the dose ${ }^{16}$ Ellipta is also a multidose DPI for the delivery of umeclidinium bromide (LAMA) with vilanterol (LABA), or fluticasone furoate, an inhaled corticosteroid, and vilanterol
(LABA), or umeclidinium bromide (LAMA) alone. ${ }^{17}$ Breezhaler is a single-dose capsule inhaler for the delivery of glycopyrronium bromide (LAMA) with indacaterol (LABA), or glycopyrronium bromide (LAMA) alone, or indacaterol (LABA) alone. Inhalation causes the capsule to vibrate in the Breezhaler device and such vibrations act as a form of acoustic feedback for the release of medication from the device.

The objectives of this study were to compare the satisfaction and preference, as well as error occurrence with use of these three DPI devices by healthy subjects in Hong Kong.

\section{Subjects and methods Subjects and study design}

This was a single-centred, randomized, closed-labeled study. One hundred and thirty healthy Hong Kong Chinese subjects aged $\geq 40$ years who had no previous diagnosis of COPD or asthma and no experience of using DPIs were recruited to the study, thus ruling out any bias on inhaler operation. Subjects who had any condition which impaired their ability to operate the inhaler, who had any history of chronic respiratory diseases, and who were unable to read the instructions, answer subject-reported questionnaires or give written informed consent were excluded from the study. Subjects were randomized with respect to the sequence of learning and the use of the three placebo DPI devices, namely, Genuair, Ellipta and Breezhaler, such that each subject undertook one of the sequences depicted in Figure 1.

Placebo devices of Genuair and Ellipta did not contain any active medication or powder, and in the case of the Breezhaler, empty capsules were used in place of medication-containing capsules. The brand names of the inhalers were not disclosed to the subjects. Subjects were first asked to read a set of written instructions for one of the DPIs and then demonstrate the

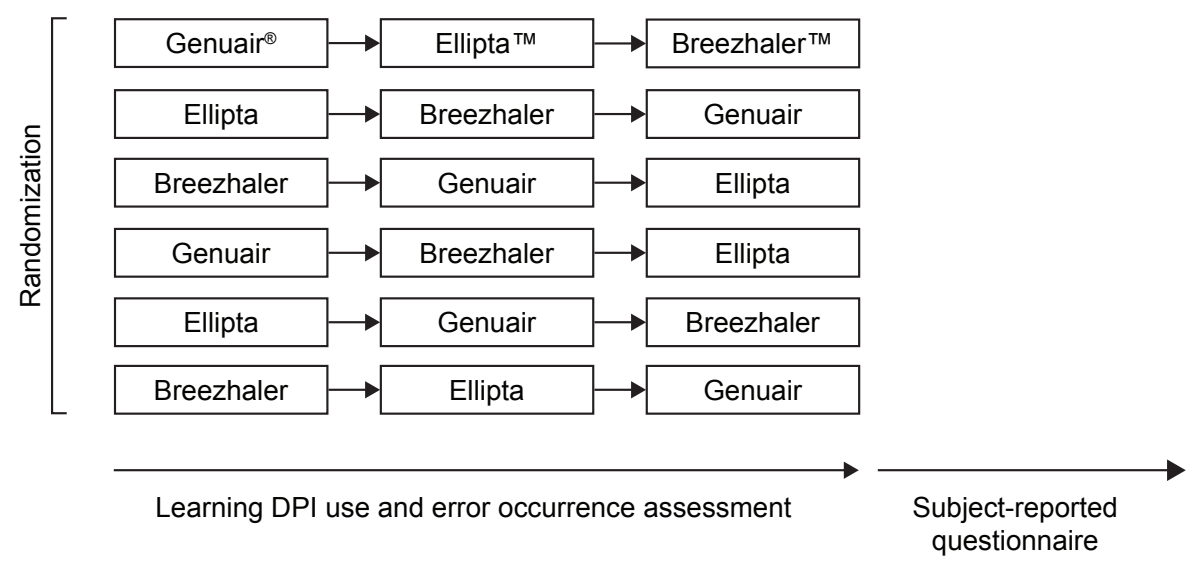

Figure I A schematic diagram showing randomization and sequence of learning to use the different DPI devices. Abbreviation: DPI, dry powder inhaler. 
use of the DPI to an assessor. The demonstration was evaluated by the assessor who noted the errors committed based on a checklist (Table S1). Subjects were then given a physical demonstration by the assessor on how to use the DPI with a pre-recorded verbal explanation. Subjects were asked to demonstrate the use of the DPI for a second time, while the assessor observed and noted any error committed. The two learning stages were repeated for the remaining two inhalers. The errors were classified into critical and non-critical errors (Table S1). Critical errors were defined as errors which prevented the subjects from inhaling any of the medications contained in the DPI. Non-critical errors were defined as errors which caused suboptimal administration of the drug or use of the DPI, although the subject could still inhale part of the dose. One main assessor and two assistants were employed to evaluate the errors. The main assessor demonstrated the borderline actions between the correct actions and errors to the assistant. All of them assessed several subjects together at the beginning of the project to ensure the standard was agreed. Then the three assessors evaluated the errors individually. After the subjects had demonstrated the use of all three DPIs, they completed a questionnaire to indicate their level of satisfaction and preference for various attributes of the three inhalers, using a Likert-type scale with a score from 1 to 7 . Subjects were also asked, using a 100-point scale for overall satisfaction, to indicate how willing they would be to use each DPI if they were diagnosed with COPD.

The study protocol was approved by the Research Ethics Subcommittee of the University of Hong Kong School of Professional and Continuing Education. Written consent was provided by each subject prior to the commencement of the study procedure.

\section{Statistical analyses}

Age of subjects and satisfactory scores were presented as mean \pm standard error of the mean. The occurrence of one or more critical errors during the use of each DPI was analyzed by McNemar's test. Briefly, the three DPIs were compared in a pair-wise manner, that is, Genuair vs Ellipta, Ellipta vs Breezhaler and Genuair vs Breezhaler. In each comparison between two DPIs A vs B, subjects were classified into four groups: 1) committing critical errors when using both $\mathrm{A}$ and $\mathrm{B}, 2$ ) committing critical errors when using A only (the number of which is designated $a$ ), 3) committing critical errors when using B only (designated $b$ ) and 4) committing no errors when using A or B. The chi-square statistics was calculated by the formula $(a-b)^{2} /(a+b)$.

Satisfaction scores for each attribute and overall satisfaction scores for each DPI were analyzed for statistical significance by one-way analysis of variance followed by post hoc Tukey's test. For comparisons of scores for each attribute between male and female subjects and between subjects $<60$ and $\geq 60$ years of age, two-way analysis of variance followed by Sidak's multiple comparisons test was used. Minimally important difference was analyzed by comparing the differences in satisfactory score for each attribute between DPIs with the SDs of the scores, with the differences $>0.2 \mathrm{SD}$ and $<0.5$ SD being a small effect and $\geq 0.5 \mathrm{SD}$ and $<0.79 \mathrm{SD}$ being a medium effect. ${ }^{18}$ Distribution of DPI preference was analyzed by the procedure described in Sharpe's study ${ }^{19}$ for deviation from uniform distribution by the chi-square goodness-of-fit tests. In order to determine the DPI causing the deviation, we computed the standardized residuals, $R$. When the absolute value of the standardized residual exceeds 2 , this shows lack of fit in the cells, with $p \leq 0.05 .^{20}$

\section{Results Subjects}

Data on satisfaction, preference and error occurrence for the three DPIs were collected from a total of 130 healthy Chinese subjects (aged $41-84$ years, mean age $=59.82 \pm 0.88$ years) consisting of 61 males (aged 42-84 years, mean age $=60.98 \pm 0.93$ years) and 69 females (aged $41-79$ years, mean age $=58.78 \pm 0.82$ years $)$.

\section{Satisfaction}

Subjects were asked to evaluate and indicate their satisfaction on various attributes of the three DPIs using a seven-point Likert-type scale (Figure 2). In terms of comfort of the DPIs, the satisfaction score for Breezhaler was significantly higher than that for Ellipta (5.13 \pm 0.13 vs $4.70 \pm 1.65, p=0.047)$. However, the satisfaction score for Breezhaler in terms of ease of dose preparation was lowest among the DPIs, being significantly lower than those of both Ellipta ( $4.75 \pm 0.15$ vs $5.24 \pm 0.15, p=0.0463)$ and Genuair $(4.75 \pm 0.15$ vs $5.39 \pm 0.13$, $p=0.0038)$.

When being asked about the clarity of the DPIs to indicate correct dose preparation, subjects indicated significantly

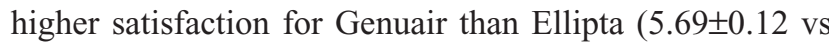
$5.25 \pm 0.15, p=0.0120)$. In terms of clarity of DPIs to indicate correct inhalation, subjects had greater satisfaction with Genuair compared with Ellipta $(5.65 \pm 0.13$ vs $5.11 \pm 0.15$, $p=0.0014)$. The satisfaction score on confidence to have inhaled the entire dose when using the DPIs was highest for Genuair compared with Ellipta $(5.43 \pm 0.13$ vs $4.62 \pm 0.15$, $p \leq 0.0001)$ and Breezhaler $(5.43 \pm 0.13$ vs $4.98 \pm 0.13$, $p=0.0328$ ). 


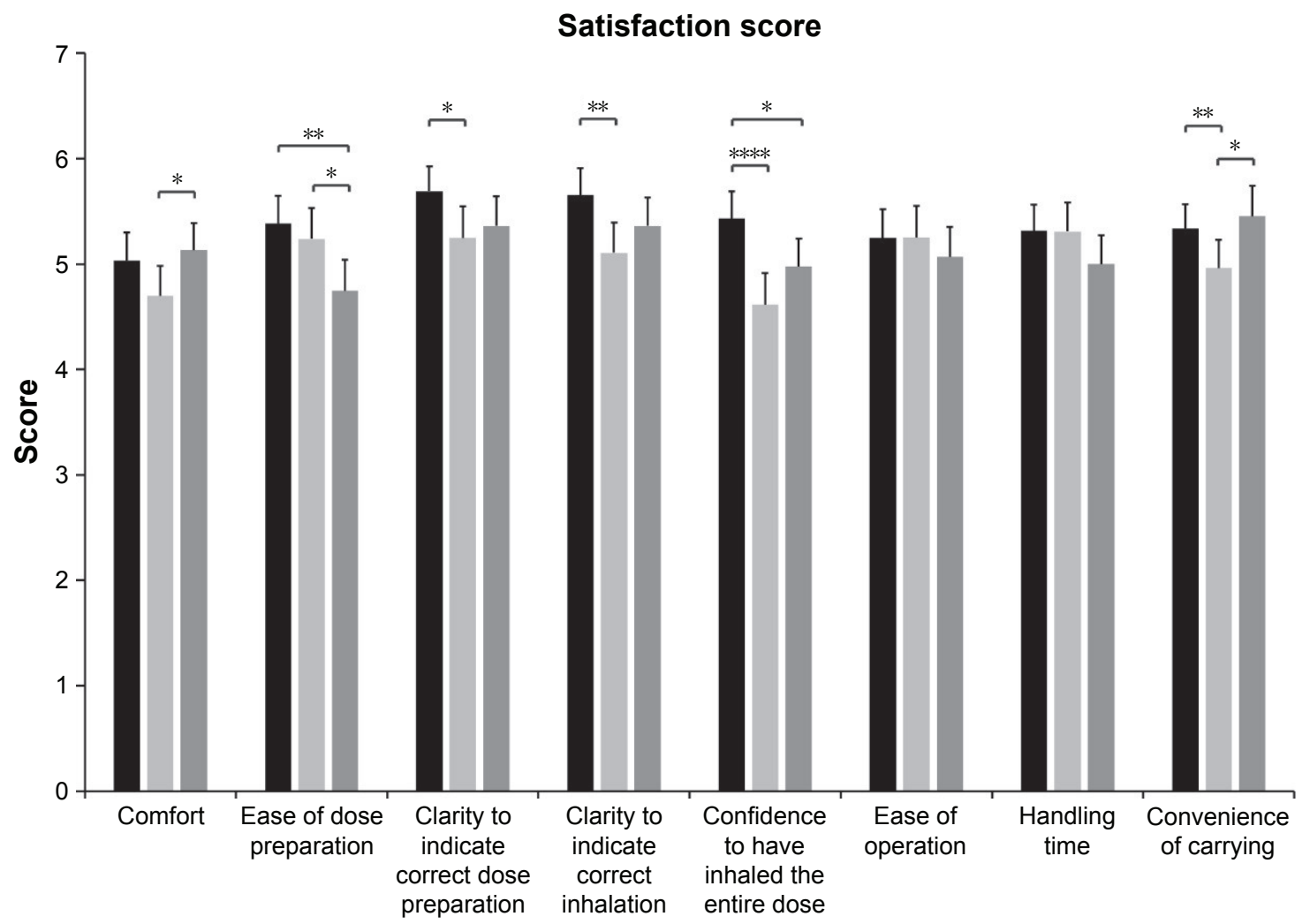

- Genuair $^{\circledR} \quad$ Ellipta $^{\text {TM }}$ Breezhaler ${ }^{\text {TM }}$

Figure 2 Satisfaction scores on different attributes of the three DPIs using a seven-point Likert-type scale. Notes: Mean values are plotted and the error bars represent the SEM. $*_{p} \leq 0.05 ; * * p \leq 0.01 ; * * * * p \leq 0.000$ I.

Abbreviations: DPIs, dry powder inhalers; SEM, standard error of the mean.

No significant difference was observed in the satisfaction score for ease of operation and handling time among the three DPIs (Figure 2). Finally, subjects considered Breezhaler (5.45 \pm 0.15 vs $4.96 \pm 0.14, p=0.0304)$ and Genuair $(5.34 \pm 0.12$ vs $4.96 \pm 0.14, p=0.0087$ ) to be more convenient to carry than Ellipta. Similar trends were seen in the subanalysis by gender and age (younger than 60 years of age vs 60 years of age and above) and these data can be found in Figures S1 and S2. An analysis that directly compares the effects of gender (male vs female) and age ( $<60 \mathrm{vs} \geq 60$ years of age) on the satisfactory scores of the different attributes is provided in Figures S3 and S4, respectively.

The satisfaction score data were further analyzed to determine whether the effect sizes exceed the threshold for clinical relevance by considering the minimally important difference using a distribution-based method. ${ }^{18,21}$ Conventional benchmarks were used, wherein an effect size $>0.2 \mathrm{SD}$ and $<0.5 \mathrm{SD}$ is a small effect and an effect size $\geq 0.5 \mathrm{SD}$ and $<0.79 \mathrm{SD}$ is a medium effect. After analyzing the differences between the satisfaction scores of each DPI for each attribute (Tables 1 and S2), we found that all effects which reached statistical significance were small effects, with the exception of clarity to indicate correct inhalation, with Genuair being more superior than Ellipta and approaching a medium effect.

The overall satisfaction score, used as a measure to indicate the willingness of subjects to use each of the DPIs

Table I Differences of satisfactory scores between each DPI for each attribute

\begin{tabular}{|c|c|c|c|}
\hline Attribute & $\begin{array}{l}\text { Genuair }^{\circledR}- \\
\text { Ellipta }^{\mathrm{TM}}\end{array}$ & $\begin{array}{l}\text { Ellipta- } \\
\text { Breezhaler }^{\mathrm{TM}}\end{array}$ & $\begin{array}{l}\text { Genuair- } \\
\text { Breezhaler }\end{array}$ \\
\hline Comfort & 0.3308 & $0.4308^{a}$ & 0.1000 \\
\hline Ease of dose preparation & 0.1462 & $0.4923^{\mathrm{a}}$ & $0.6385^{\mathrm{a}}$ \\
\hline $\begin{array}{l}\text { Clarity to indicate } \\
\text { correct dose preparation }\end{array}$ & $0.4462^{\mathrm{a}}$ & 0.1154 & 0.3308 \\
\hline $\begin{array}{l}\text { Clarity to indicate } \\
\text { correct inhalation }\end{array}$ & $0.5462^{\mathrm{a}}$ & 0.2538 & 0.2923 \\
\hline $\begin{array}{l}\text { Confidence to have } \\
\text { inhaled the entire dose }\end{array}$ & $0.8154^{b}$ & 0.3615 & $0.4538^{a}$ \\
\hline Ease of operation & 0.0077 & 0.1846 & 0.1769 \\
\hline Handling time & 0.0077 & 0.3077 & 0.3154 \\
\hline Convenience of carrying & $0.3769^{a}$ & $0.4923^{\mathrm{a}}$ & 0.1154 \\
\hline Overall satisfaction score & $5.5615^{\mathrm{a}}$ & 2.2615 & $\left.7.823\right|^{a}$ \\
\hline
\end{tabular}

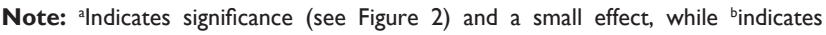
significance and an effect approaching medium.

Abbreviation: DPI, dry powder inhaler. 


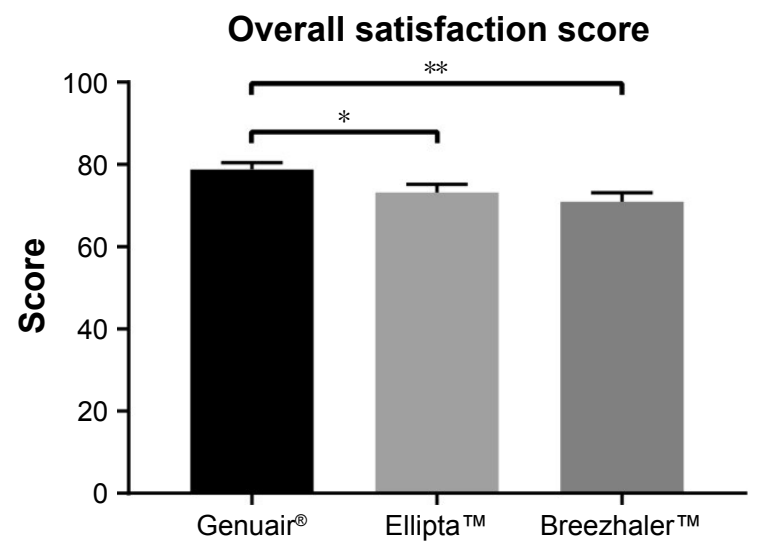

Figure 3 Overall satisfaction scores on a $0-100$ scale to indicate the willingness of subjects to use each DPI $\left({ }^{*} p \leq 0.05 ; * * p \leq 0.0\right.$ I).

Abbreviation: DPI, dry powder inhaler.

if they were diagnosed with COPD, was significantly higher for Genuair than for both Ellipta (78.79 \pm 1.70 vs $73.23 \pm 1.94$, $p=0.0132)$ and Breezhaler $(78.79 \pm 1.70$ vs $70.97 \pm 2.15$, $p=0.0063$; Figure 3).

\section{Preferences}

Subjects were asked to indicate their preferred inhaler for each attribute evaluated (Table 2). The distribution of preference for each attribute was analyzed for significant deviations from uniform distribution (ie, 33.3\% for each DPI) using chi-square tests. ${ }^{17}$

Genuair was the preferred DPI in terms of clarity to indicate correct dose preparation $(38.5 \%, R=2.137)$, clarity to indicate correct inhalation $(37.7 \%, R=2.299)$ and confidence to have inhaled the entire dose $(42.3 \%, R=2.824)$. In terms of confidence to have inhaled the entire dose, the standardized residual for Ellipta was -2.716 , indicating a significant lack of preference $(16.2 \%)$. Breezhaler was the preferred DPI for convenience of carrying, as preferred by $42.3 \%$ of subjects ( $R=2.372$ ), while Ellipta was less preferred by subjects for this attribute $(16.2 \%, R=-3.004)$. For the attributes of comfort, ease of dose preparation, ease of operation and handling time, the distributions were not found to deviate significantly.

\section{Error occurrence during use of DPIs}

After reading the instructions, the highest number of subjects committing one or more critical errors was with Breezhaler (96 [73.8\%]) followed by Genuair (70 [53.8\%]) and then Ellipta (33 [25.4\%]), as shown in Figure 4A. The likelihood for subjects to commit critical errors when using Breezhaler was higher than those when using either Genuair ( $p \leq 0.0001$, chi-square statistic $=15.36$ ) or Ellipta ( $p \leq 0.0001$, chi-square statistic $=55.90)$. Similarly, subjects were more likely to commit one or more critical errors when using Genuair than Ellipta ( $p \leq 0.0001$, chi-square statistic=27.94; Figure 4B).

For all three DPIs, the number of subjects who committed critical errors reduced after visual demonstration with verbal instructions. The highest number of subjects committing one or more critical errors, after the demonstration, was with Breezhaler (30 [23.1\%]) followed by Ellipta (12 [9.2\%]) and then Genuair (11 [8.5\%]), as shown in Figure 4A. The likelihood for subjects to commit critical errors when using Breezhaler was still higher than for those using either Genuair ( $p \leq 0.001$, chi-square statistic=12.45) or Ellipta ( $p \leq 0.01$, chi-square statistic=10.80). There was no significant difference between Genuair and Ellipta ( $p=0.8084$, chi-square statistic $=0.0588$; Figure 4B).

The number and percentage of subjects who committed each non-critical error is depicted in Table 3. The total number of non-critical errors committed during use of each DPI is presented in Table S3.

\section{Discussion}

The correct and preferred use of DPIs is essential to deliver the relevant drugs appropriately to the patient. Besides the efficacy of bronchodilators and corticosteroids,

Table 2 Preference of subjects for different attributes of the three DPIs

\begin{tabular}{|c|c|c|c|c|}
\hline \multirow[t]{2}{*}{ Attributes } & \multirow{2}{*}{$\begin{array}{l}p \text {-value of chi- } \\
\text { square goodness- } \\
\text { of-fit test }\end{array}$} & \multicolumn{3}{|c|}{$\%$ Preference (standardized residual, $R$ ) } \\
\hline & & Genuair $^{\circledR}$ & Ellipta $^{\mathrm{TM}}$ & Breezhaler ${ }^{\mathrm{TM}}$ \\
\hline Comfort & 0.097 & $33.8(0.801)$ & $21.5(-1.76 \mid)$ & $34.6(0.97 I)$ \\
\hline Ease of dose preparation & 0.569 & $29.2(-0.265)$ & $34.6(0.847)$ & $27.7(-0.582)$ \\
\hline Clarity to indicate correct dose preparation ${ }^{\mathrm{a}}$ & 0.014 & $38.5(2.137)$ & $19.2(-1.973)$ & $27.7(-0.164)$ \\
\hline Clarity to indicate correct inhalation ${ }^{\mathrm{a}}$ & 0.013 & $37.7(2.299)$ & $19.2(-1.738)$ & $24.6(-0.56 I)$ \\
\hline Confidence to have inhaled the entire dose ${ }^{a}$ & $<0.0001$ & $42.3(2.824)$ & $16.2(-2.716)$ & $28.5(-0.109)$ \\
\hline Ease of operation & 0.294 & $33.1(0.474)$ & $34.6(0.791)$ & $24.6(-1.265)$ \\
\hline Handling time & 0.116 & $32.3(0.764)$ & $33.1(0.927)$ & $20.8(-1.69 \mid)$ \\
\hline Convenience of carrying ${ }^{\mathrm{a}}$ & 0.001 & $33.8(0.632)$ & $16.2(-3.004)$ & $42.3(2.372)$ \\
\hline
\end{tabular}

Note: aSignificant deviation from uniform distribution, with $p \leq 0.05, R>2$ or $R<-2$.

Abbreviation: DPIs, dry powder inhalers. 


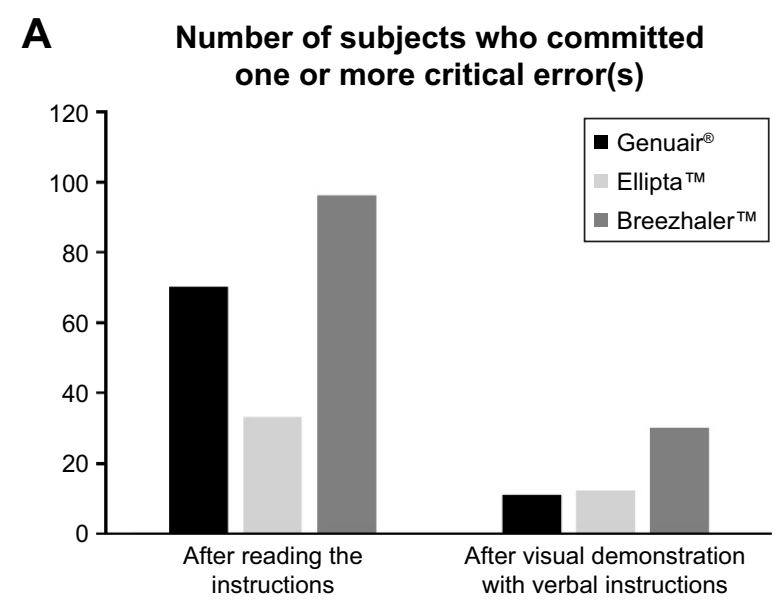

\section{B Number of subjects who committed one or more critical error(s) during use of one of the three DPIs after reading the instructions}

\begin{tabular}{|c|c|c|c|c|c|c|c|c|c|c|c|}
\hline & & \multicolumn{2}{|c|}{ Ellipta } & & & \multicolumn{2}{|c|}{ Breezhaler } & & & \multicolumn{2}{|c|}{ Breezhaler } \\
\hline & & Yes & No & & & Yes & No & & & Yes & No \\
\hline \multirow[t]{2}{*}{ Genuair } & Yes & 27 & 43 & \multirow[t]{2}{*}{ Ellipta } & Yes & 29 & 4 & \multirow[t]{2}{*}{ Genuair } & Yes & 61 & 9 \\
\hline & No & 6 & 54 & & No & 67 & 30 & & No & 35 & 25 \\
\hline \multirow{2}{*}{\multicolumn{3}{|c|}{$\begin{array}{l}p \text {-value: } \\
\text { Chi-square statistic: }\end{array}$}} & $1.25 \mathrm{e}-07 *$ & \multirow{2}{*}{\multicolumn{3}{|c|}{$\begin{array}{l}p \text {-value: } \\
\text { Chi-square statistic: }\end{array}$}} & $7.62 \mathrm{e}-14 *$ & \multirow{2}{*}{\multicolumn{3}{|c|}{$\begin{array}{l}p \text {-value: } \\
\text { Chi-square statistic: }\end{array}$}} & $8.87 e-5^{*}$ \\
\hline & & & 27.939 & & & & 55.901 & & & & 15.364 \\
\hline
\end{tabular}

After visual demonstration with verbal instructions

\begin{tabular}{|c|c|c|c|c|c|c|c|c|c|c|c|}
\hline & \multicolumn{3}{|c|}{ Ellipta } & & & \multicolumn{2}{|c|}{ Breezhaler } & & & \multicolumn{2}{|c|}{ Breezhaler } \\
\hline & & Yes & No & & & Yes & No & & & Yes & No \\
\hline \multirow[t]{2}{*}{ Genuair } & Yes & 3 & 8 & \multirow[t]{2}{*}{ Ellipta } & Yes & 6 & 6 & \multirow[t]{2}{*}{ Genuair } & Yes & 6 & 5 \\
\hline & No & 9 & 110 & & No & 24 & 94 & & No & 24 & 95 \\
\hline \multicolumn{3}{|c|}{$\begin{array}{l}\text { p-value: } \\
\text { Chi-square statistic: }\end{array}$} & $\begin{array}{l}0.8084 \\
0.0588\end{array}$ & \multicolumn{3}{|c|}{$\begin{array}{l}p \text {-value: } \\
\text { Chi-square statistic: }\end{array}$} & $0.00102 *$ & \multicolumn{3}{|c|}{$\begin{array}{l}p \text {-value: } \\
\text { Chi-square statistic: }\end{array}$} & $\begin{array}{l}0.00042^{*} \\
12448\end{array}$ \\
\hline
\end{tabular}

Figure 4 (A) Number of subjects who committed one or more critical errors during the two learning stages. (B) McNemar's tests for the number of subjects who committed one or more critical errors during the two learning stages.

Note: ${ }^{*} p \leq 0.05$.

Abbreviation: DPIs, dry powder inhalers.

patient preference and the skills required in using inhaler devices can affect the effectiveness of the treatment. It is important that an inhaler device is easy to use, so that the correct dosage is administered. In this study, 130 healthy subjects were recruited and the numbers of male $(n=61)$ and female $(n=69)$ subjects were evenly distributed. The subjects were aged $41-84$ years with the average age $59.82 \pm 0.88$ years. As the prevalence of COPD is higher in people aged 60 years or above compared to those aged $40-60$ years, ${ }^{22,23}$ the age distribution of our subjects also covered a cross section of the high and low prevalence groups. Besides disease conditions such as Huntington's chorea, stroke and so on, which cause dysfunction of brain, ${ }^{24,25}$ degeneration of brain structure with aging is highly related to reduced dexterity and cognitive function. ${ }^{26,27}$ Thus, ease of use is very important for elderly patients. The study did not include the education level of the subjects. Although education background might affect the ability to understand instructions, Blasi et al reported no difference in the time required to perform a correct inhalation of Genuair between different education levels. ${ }^{28}$
In our study, subjects rated Breezhaler with the highest score for "comfort" (Figure 2). Interestingly, the score given by males did not show any significant difference among the three DPIs, and the high score of Breezhaler for "comfort" was mainly contributed by females (Figure S2). This could be related to the shape and size of Breezhaler. Compared to the other two DPIs, Breezhaler is smaller and the medicine is not built into the device, which could also explain the higher score for "convenience of carrying". However, the design seems to also affect dose preparation, as the user required extra steps to put a capsule into Breezhaler. The subjects in our study gave a significantly lower score for Breezhaler for "ease of dose preparation".

Both Ellipta and Genuair are equipped with acoustic feedback mechanism to indicate that a dose has been correctly prepared. Genuair also has a visual feedback mechanism in the form of a red/green window to indicate empty and loaded dose. These visual and acoustic feedback mechanisms also indicate correct inhalation of a dose when enough inhalation flow is generated in Genuair. The higher scores for Genuair in "clarity to indicate correct dose preparation" and 
Table 3 Number and percentage of subjects who committed non-critical errors

\begin{tabular}{|c|c|c|}
\hline Non-critical errors & $\begin{array}{l}\text { After } \\
\text { reading the } \\
\text { instructions }\end{array}$ & $\begin{array}{l}\text { After visual } \\
\text { demonstration with } \\
\text { verbal instructions }\end{array}$ \\
\hline \multicolumn{3}{|l|}{ Genuair $^{\circledR}$} \\
\hline Did not hold the inhaler at the correct position during dose preparation & $34(26.15)$ & $4(3.08)$ \\
\hline Did not breathe out completely before inhalation ${ }^{\mathrm{a}}$ & $52(40.00)$ & $19(14.62)$ \\
\hline Breathed into the inhaler before inhalation & II (8.46) & $4(3.08)$ \\
\hline Did not hold the inhaler at the correct position during inhalation & $2(1.54)$ & $0(0.00)$ \\
\hline Did not breathe in strongly and deeply during inhalation ${ }^{a}$ & $52(40.00)$ & $5(3.85)$ \\
\hline Stopped breathing in when a "click" sound was heard & $9(6.92)$ & $14(10.77)$ \\
\hline Pressed the button during or after inhalation & $29(22.31)$ & $14(10.77)$ \\
\hline Did not hold breath for long enough after inhalation ${ }^{\mathrm{a}}$ & $49(37.69)$ & $20(15.38)$ \\
\hline Breathed out quickly and strongly after holding the breath/breathed out through the mouth & $32(24.62)$ & $28(21.54)$ \\
\hline Did not replace the protective cap & $10(7.69)$ & $4(3.08)$ \\
\hline \multicolumn{3}{|l|}{ Ellipta ${ }^{\mathrm{TM}}$} \\
\hline Opened the cover and closed it without inhalation & $5(3.85)$ & $3(2.31)$ \\
\hline Did not hold the inhaler at the correct position during dose preparation & $15(11.54)$ & $8(6.15)$ \\
\hline Shook the inhaler after loading a dose & $9(6.92)$ & $0(0.00)$ \\
\hline Did not breathe out completely before inhalation ${ }^{a}$ & $66(50.77)$ & $21(16.15)$ \\
\hline Breathed into the inhaler before inhalation & $9(6.92)$ & $7(5.38)$ \\
\hline Blocked the air vent with fingers during inhalation & $14(10.77)$ & $2(1.54)$ \\
\hline Did not hold the inhaler at the correct position during inhalation & $15(11.54)$ & II (8.46) \\
\hline Did not breathe in strongly and deeply during inhalation & $49(37.69)$ & $27(20.77)$ \\
\hline Did not hold breath for long enough after inhalation ${ }^{a}$ & $65(50.00)$ & $25(19.23)$ \\
\hline Breathed out quickly and strongly after holding the breath ${ }^{\mathrm{a}}$ & $52(40.00)$ & $23(17.69)$ \\
\hline \multicolumn{3}{|l|}{ Breezhaler ${ }^{T M}$} \\
\hline Did not close the inhaler properly after placing the capsule (with a "click" sound) & I (0.77) & I (0.77) \\
\hline Did not hold the inhaler at the correct position during dose preparation & $7(5.38)$ & $7(5.38)$ \\
\hline Pressed the two side buttons more than once & $33(25.38)$ & II (8.46) \\
\hline Took inhalation posture without releasing the side buttons fully & $18(13.85)$ & $6(4.62)$ \\
\hline Did not breathe out completely before inhalation ${ }^{a}$ & $58(44.62)$ & $17(13.08)$ \\
\hline Breathed into the inhaler before inhalation & $4(3.08)$ & $6(4.62)$ \\
\hline Did not hold the inhaler at the correct position during inhalation & $10(7.69)$ & $7(5.38)$ \\
\hline In case a whirring noise was not heard, did not open the inhaler to loosen the capsule ${ }^{a}$ & $37(28.46)$ & $15(11.54)$ \\
\hline When checking a stuck capsule, did not loosen the capsule by tapping the base of the inhaler & $4(3.08)$ & $2(1.54)$ \\
\hline Did not hold breath after inhalation for long enough ${ }^{\mathrm{a}}$ & $42(32.31)$ & $16(12.3 \mid)$ \\
\hline Breathed out quickly and strongly after holding the breath & $33(25.38)$ & $20(15.38)$ \\
\hline Removed the empty capsule by touching the capsule in the inhaler & $8(6.15)$ & $4(3.08)$ \\
\hline Did not replace the cap & $17(13.08)$ & $8(6.15)$ \\
\hline
\end{tabular}

Notes: Data show the number (percentage) of subjects. ${ }^{\text {T}}$ The three most common non-critical errors for each DPI are indicated.

Abbreviation: DPI, dry powder inhaler.

"clarity to indicate correct inhalation" (Figure 2) reflected that subjects were more satisfied with the device's feedback mechanism. The subjects also rated a significantly higher score for Genuair in "confidence to have inhaled the entire dose". Rajan and Gogtay suggested that confidence was important to new users of DPI, as this would lead to better adherence to therapy. ${ }^{29}$ The clearer indications of dose preparation and correct inhalation together with higher confidence could explain the significantly higher overall satisfaction score for Genuair. A previous study in Germany, Spain and the UK compared the satisfaction of COPD patients on Genuair and Breezhaler. ${ }^{30}$ The results also showed that a higher overall satisfaction score was found in Genuair than Breezhaler.
The satisfaction scores of different attributes were analyzed by gender and age (Figures S1 and S2). The pattern of the scores for the three DPIs was similar between males and females. When analyzing the satisfaction scores according to age groups, the patterns were also very similar. However, in terms of "ease of operation" and "handling time", the younger group (aged 40-60) reported a significantly higher score for Ellipta than Breezhaler, while the older group (aged 60 and above) gave a higher score to Breezhaler. The satisfaction scores of different attributes were further compared by male vs female and the younger group vs older group (Figures S3 and S4). The only significant result was found in "ease of operation", where the older group gave a significantly lower score to Ellipta. These results suggested 
that the handling procedures of Ellipta may be difficult for the older group.

The errors during the use of DPIs were also evaluated based on the list of errors (Table S1). The handling procedures and complexity of the three DPIs are different, and thus, the error list is designed based on the instruction manual of each DPI. After reading the instructions only, subjects were less likely to commit critical errors when using Ellipta than Genuair or Breezhaler (Figure 4B). The data suggest that Ellipta may be easier to learn by reading the instructions alone. Regardless of reading the instructions only or after observation of the visual demonstration with verbal instructions, the number of subjects committing critical errors was higher with Breezhaler. These results may indicate that the design of Breezhaler is more complex, especially for new users. Interestingly, subjects also gave a lower satisfaction score for Breezhaler on "ease of operation" and "handling time" (Figure 2). A previous study in Japan also showed that the volunteers made more errors when using Breezhaler compared to Ellipta. ${ }^{17}$ It is also worth noting that visual demonstration with verbal instructions reduced the number of subjects making critical errors for each DPI to one third or lower compared to reading the instructions only, with the effect being the greatest for Genuair. This finding suggests that visual demonstration with verbal instructions is crucial to new users of DPIs. In a study conducted by Svedsater et al, subjects also reported that with briefing and demonstration, they could understand how to use DPIs even without reading the instructions. ${ }^{31}$

This study excluded subjects who had been diagnosed with COPD or asthma and had experience of using DPIs. Thus, the results would represent newly diagnosed COPD patients who are device naïve. In the study of the usability of Genuair, Blasi et al reported that there was no difference in the time required to perform a correct inhalation when considering the different previous experience of inhaler devices. ${ }^{28}$ However, patients' experience of using DPI may affect their satisfaction. The results could be used as reference for future validation studies in COPD patients with previous experience in using DPIs. A dose counter is found in Genuair and Ellipta to indicate the number of doses left in the device. The satisfaction to this function was not tested, as the subjects demonstrated the use of each DPI for only two times.

\section{Conclusion}

The results of our study showed that each DPI has its own user advantages: Breezhaler seemed to be more comfortable to use and easy to carry. Device-naive users made less critical errors when using Ellipta after reading the instructions only. Genuair gave significantly better indications of correct dose preparation and dose inhalation. Overall, healthy volunteers had the greatest satisfaction scores when using Genuair. This is important, as satisfaction might improve patient compliance to inhaler therapy. Instead of learning to use a DPI by reading the instructions only, visual demonstration with verbal instructions given by health care professionals is crucial as they can reduce the critical errors during inhaler use. These results cannot be applied at the individual level, so good practice should be followed.

\section{Acknowledgments}

We would like to thank Mr Kwok Yan Ng, University of Hong Kong, School of Biological Sciences for his help in recruiting participants. We appreciate the support from Dr Hiu Fai Law with the statistical analysis of the data.

\section{Disclosure}

The authors report no conflicts of interest in this work.

\section{References}

1. Barnes PJ. Introduction: how can we improve asthma management? Curr Med Res Opin. 2005;21(Suppl 4):S1-S3.

2. Cross S. Asthma inhalation delivery systems: the patient's viewpoint. J Aerosol Med. 2001;14(Suppl 1):S3-S7.

3. Magnussen H. Novolizer: how does it fit into inhalation therapy? Curr Med Res Opin. 2005;21(Suppl 4):S39-S46; discussion S47.

4. Melani AS. Inhalatory therapy training: a priority challenge for the physician. Acta Biomed. 2007;78(3):233-245.

5. Dal Negro RW, Povero M. Acceptability and preference of three inhalation devices assessed by the Handling Questionnaire in asthma and COPD patients. Multidiscip Respir Med. 2015;11:7.

6. Virchow JC. Guidelines versus clinical practice-which therapy and which device? Respir Med. 2004;98(Supp1 B):S28-S34.

7. Restrepo RD, Alvarez MT, Wittnebel LD, et al. Medication adherence issues in patients treated for COPD. Int J Chron Obstruct Pulmon Dis. 2008;3(3):371-384.

8. Lavorini F, Magnan A, Dubus JC, et al. Effect of incorrect use of dry powder inhalers on management of patients with asthma and COPD. Respir Med. 2008;102(4):593-604.

9. Souza ML, Meneghini AC, Ferraz E, Vianna EO, Borges MC. [Knowledge of and technique for using inhalation devices among asthma patients and COPD patients]. J Bras Pneumol. 2009;35(9):824-831. Portuguese.

10. Raherison C, Girodet PO. Epidemiology of COPD. Eur Respir Rev. 2009; 18(114):213-221.

11. Chrystyn H, Small M, Milligan G, Higgins V, Gil EG, Estruch J. Impact of patients' satisfaction with their inhalers on treatment compliance and health status in COPD. Respir Med. 2014;108(2):358-365.

12. Lareau SC, Yawn BP. Improving adherence with inhaler therapy in COPD. Int J Chron Obstruct Pulmon Dis. 2010;5:401-406.

13. Hodder R, Price D. Patient preferences for inhaler devices in chronic obstructive pulmonary disease: experience with Respimat Soft Mist inhaler. Int J Chron Obstruct Pulmon Dis. 2009;4:381-390.

14. van der Palen J, Ginko T, Kroker A, et al. Preference, satisfaction and errors with two dry powder inhalers in patients with COPD. Expert Opin Drug Deliv. 2013;10(8):1023-1031. 
15. Chrystyn H, Niederlaender C. The Genuair ${ }^{\circledR}$ inhaler: a novel, multidose dry powder inhaler. Int J Clin Pract. 2012;66(3):309-317.

16. Magnussen $\mathrm{H}$, Watz $\mathrm{H}$, Zimmermann I, et al. Peak inspiratory flow through the Genuair inhaler in patients with moderate or severe COPD. Respir Med. 2009;103(12):1832-1837.

17. Komase Y, Asako A, Kobayashi A, Sharma R. Ease-of-use preference for the ELLIPTA ${ }^{\circledR}$ dry powder inhaler over a commonly used singledose capsule dry powder inhaler by inhalation device-naïve Japanese volunteers aged 40 years or older. Int J Chron Obstruct Pulmon Dis. 2014;9:1365-1375.

18. Kozma CM, Slaton TL, Monz BU, Hodder R, Reese PR. Development and validation of a patient satisfaction and preference questionnaire for inhalation devices. Treat Respir Med. 2005;4(1):41-52.

19. Sharpe D. Your chi-square test is statistically significant: now what? Pract Assess Res Eval. 2015;20(8):1-10.

20. Agresti A. An Introduction to Categorical Data Analysis. Hoboken, New Jersey, USA. Wiley; 2007.

21. Guyatt GH, Osoba D, Wu AW, Wyrwich KW, Norman GR; Clinical Significance Consensus Meeting Group. Methods to explain the clinical significance of health status measures. Mayo Clin Proc. 2002;77(4): 371-383.

22. Menezes AM, Perez-Padilla R, Jardim JR, et al; PLATINO Team. Chronic obstructive pulmonary disease in five Latin American cities (the PLATINO study): a prevalence study. Lancet. 2005;366(9500): 1875-1881.

23. Global Strategy for Diagnosis, Management, and Prevention of COPD 2016. Global Initiative for Chronic Obstructive Lung Disease - GOLD. Available from: http://goldcopd.org/global-strategy-diagnosis-management-prevention-copd-2016/. Accessed May 26, 2017.
24. Montoya A, Price BH, Menear M, Lepage M. Brain imaging and cognitive dysfunctions in Huntington's disease. J Psychiatry Neurosci. 2006;31(1):21-29.

25. Sunderland A, Bowers MP, Sluman SM, Wilcock DJ, Ardron ME. Impaired dexterity of the ipsilateral hand after stroke and the relationship to cognitive deficit. Stroke. 1999;30(5):949-955.

26. Park DC, Reuter-Lorenz P. The adaptive brain: aging and neurocognitive scaffolding. Annu Rev Psychol. 2009;60:173-196.

27. Seidler RD, Bernard JA, Burutolu TB, et al. Motor control and aging: links to age-related brain structural, functional, and biochemical effects. Neurosci Biobehav Rev. 2010;34(5):721-733.

28. Blasi F, Canonica GW, Centanni S, et al. Genuair ${ }^{\mathbb{B}}$ usability test: results of a national public survey of the elderly. COPD. 2016;13(3): 367-371.

29. Rajan SK, Gogtay JA. Ease-of-use, preference, confidence, and satisfaction with Revolizer $\left({ }^{\circledR}\right)$, a novel dry powder inhaler, in an Indian population. Lung India. 2014;31(4):366-374.

30. Pascual S, Feimer J, De Soyza A, et al. Preference, satisfaction and critical errors with Genuair and Breezhaler inhalers in patients with COPD: a randomised, cross-over, multicentre study. NPJ Prim Care Respir Med. 2015;25:15018.

31. Svedsater H, Dale P, Garrill K, Walker R, Woepse MW. Qualitative assessment of attributes and ease of use of the ELLIPTA ${ }^{\mathrm{TM}}$ dry powder inhaler for delivery of maintenance therapy for asthma and COPD. BMC Pulm Med. 2013;13:72. 


\section{Supplementary materials}

Table SI List of critical and non-critical errors for each dry powder inhaler

\begin{tabular}{|c|c|c|}
\hline & Errors & $\begin{array}{l}\text { Critical (C) or } \\
\text { non-critical (NC) }\end{array}$ \\
\hline \multicolumn{3}{|c|}{ Genuair $^{\circledast}$} \\
\hline I & Did not remove cap before inhalation & $\mathrm{C}$ \\
\hline 2 & Did not hold the inhaler at the correct position during dose preparation & NC \\
\hline 3 & Did not press the button all the way down before inhalation & C \\
\hline 4 & Did not release the button before inhalation & C \\
\hline 5 & Inhaled when the control window was still red & $\mathrm{C}$ \\
\hline 6 & Did not breathe out completely before inhalation & NC \\
\hline 7 & Breathed into the inhaler before inhalation & NC \\
\hline 8 & Did not close lips firmly around the mouthpiece & C \\
\hline 9 & Did not hold the inhaler at the correct position during inhalation & NC \\
\hline 10 & Did not breathe in strongly and deeply during inhalation & NC \\
\hline 11 & Stopped breathing in when a "click" sound was heard & NC \\
\hline 12 & Pressed the button during or after inhalation & NC \\
\hline 13 & Did not hold breath for long enough after inhalation & NC \\
\hline 14 & Breathed out quickly and strongly after holding breath/breathed out through the mouth & NC \\
\hline 15 & Did not repeat the inhalation even when the control window was green & C \\
\hline 16 & Did not replace the protective cap & NC \\
\hline \multicolumn{3}{|c|}{ Ellipta $^{\mathrm{TM}}$} \\
\hline I & Could not open the cover without instructions & C \\
\hline 2 & Opened the cover and closed it without inhalation & NC \\
\hline 3 & Did not hold the inhaler at the correct position during dose preparation & NC \\
\hline 4 & Shook the inhaler after loading a dose & NC \\
\hline 5 & No "click" sound after sliding the cover open & C \\
\hline 6 & Did not breathe out completely before inhalation & NC \\
\hline 7 & Breathed into the inhaler before inhalation & NC \\
\hline 8 & Did not close lips firmly around the mouthpiece & C \\
\hline 9 & Blocked the air vent with fingers during inhalation & NC \\
\hline 10 & Did not hold the inhaler at the correct position during inhalation & NC \\
\hline 11 & Did not breathe in strongly and deeply during inhalation & NC \\
\hline 12 & Did not hold breath for long enough after inhalation & NC \\
\hline 13 & Breathed out quickly and strongly after holding breath & NC \\
\hline 14 & Did not close the cover as far as possible & C \\
\hline \multicolumn{3}{|c|}{ Breezhaler ${ }^{\mathrm{TM}}$} \\
\hline I & Did not remove cap before inhalation & C \\
\hline 2 & Placed a capsule directly into the mouthpiece & C \\
\hline 3 & Did not close the inhaler properly after placing the capsule (with a "click" sound) & NC \\
\hline 4 & Did not press the two side buttons simultaneously until a "click" was heard before inhalation & C \\
\hline 5 & Did not hold the inhaler at the correct position during dose preparation & NC \\
\hline 6 & Pressed the two side buttons more than once & NC \\
\hline 7 & Took inhalation posture without releasing the side buttons fully & NC \\
\hline 8 & Did not breathe out completely before inhalation & NC \\
\hline 9 & Breathed into the inhaler before inhalation & NC \\
\hline 10 & Did not close lips firmly around the mouthpiece & C \\
\hline II & Did not hold the inhaler at the correct position during inhalation & NC \\
\hline 12 & Did not breathe in strongly and deeply during inhalation (no whirring noise was heard) & C \\
\hline 13 & In case a whirring noise was not heard, did not open the inhaler to loosen the capsule & NC \\
\hline 14 & When checking a stuck capsule, did not loosen the capsule by tapping the base of the inhaler & NC \\
\hline 15 & Did not hold breath after inhalation for long enough & NC \\
\hline 16 & Breathed out quickly and strongly after holding breath & NC \\
\hline 17 & Did not remove the empty capsule & C \\
\hline 18 & Removed the empty capsule by touching the capsule in the inhaler & NC \\
\hline 19 & Did not replace the cap & NC \\
\hline
\end{tabular}




\section{Satisfaction scores according to gender}

\section{Comfort}

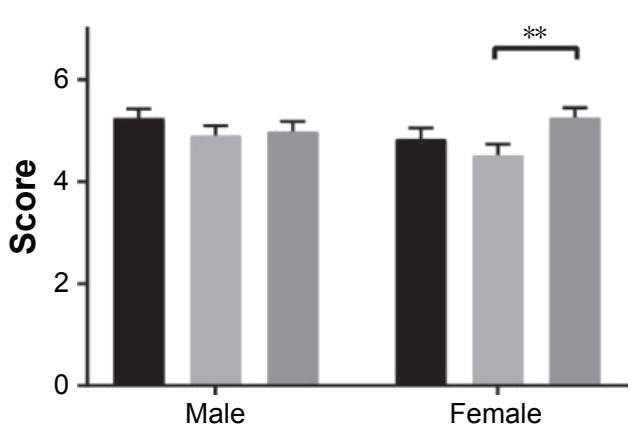

Clarity to indicate correct dose preparation

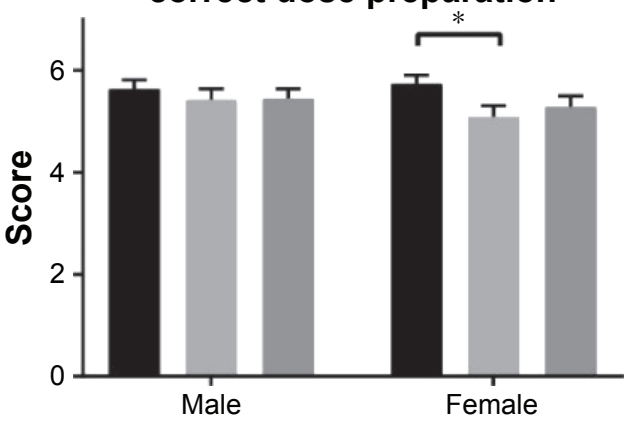

Confidence to have inhaled the entire dose

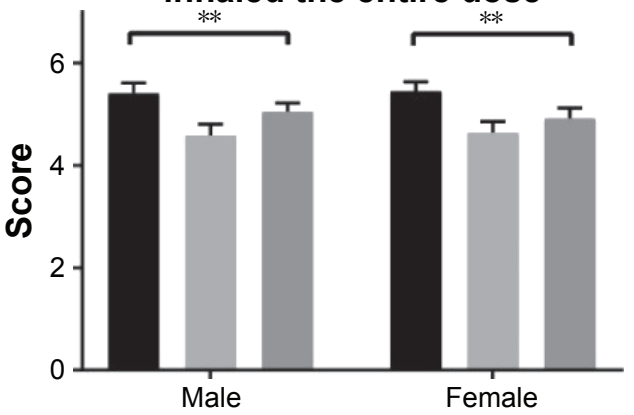

Handling time

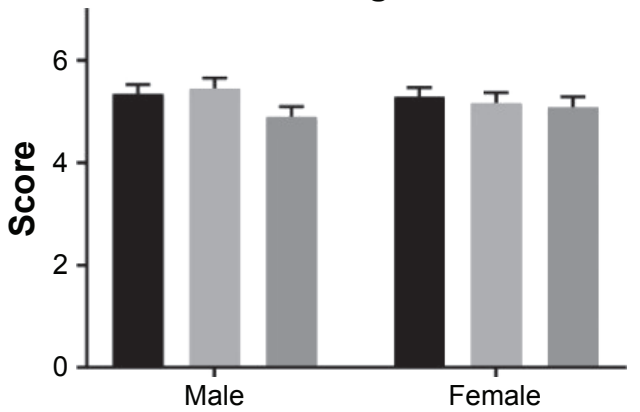

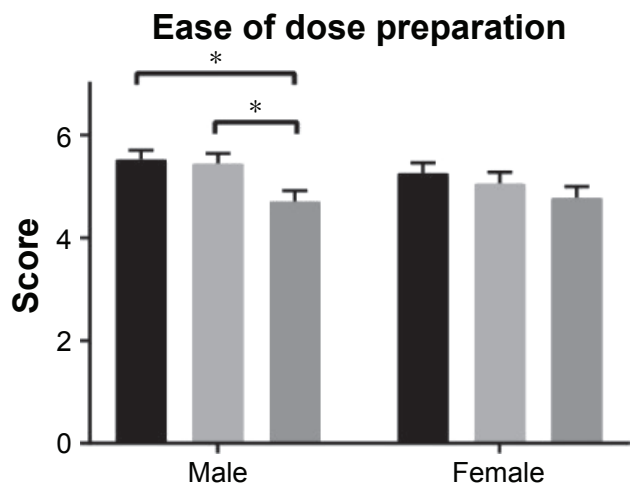

Clarity to indicate correct inhalation

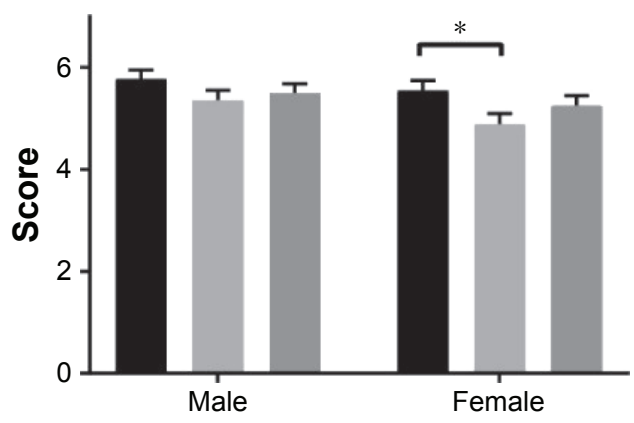

Ease of operation

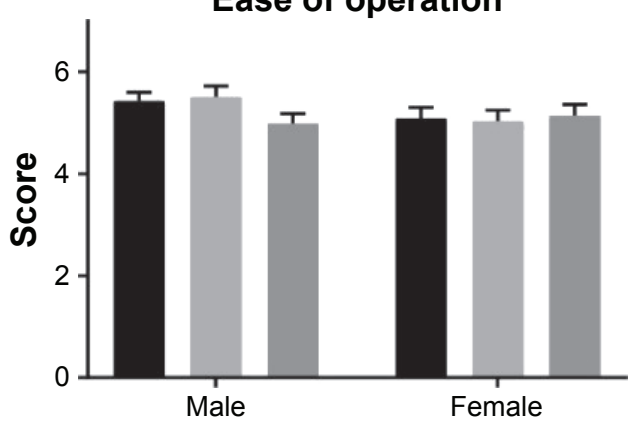

Convenience of carrying

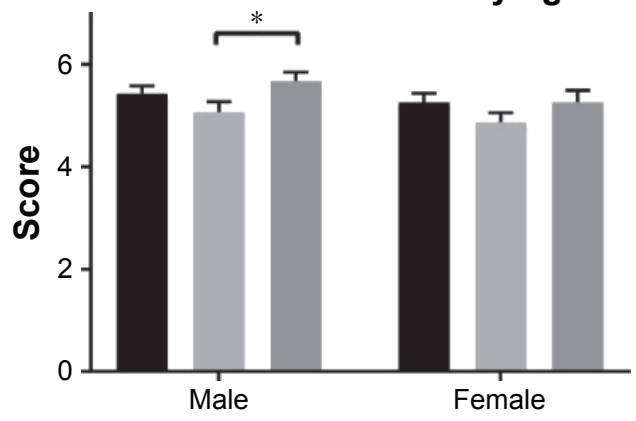

Genuair $^{\circledR} \quad$ Ellipta $^{\mathrm{TM}} \quad$ Breezhaler $^{\mathrm{TM}}$

Figure SI Satisfaction scores on different attributes of the three DPIs as evaluated by male and female subjects.

Notes: Mean values are plotted and the error bars represent the SEM. $* p \leq 0.05 ; * * \leq 0.01$.

Abbreviations: DPIs, dry powder inhalers; SEM, standard error of the mean. 
Satisfication scores according to age group

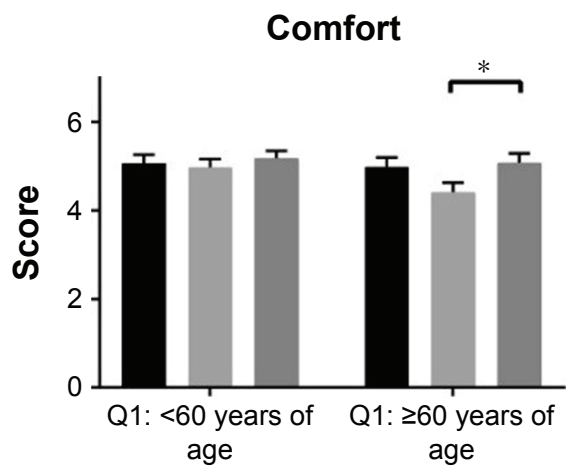

Clarity to indicate correct dose preparation

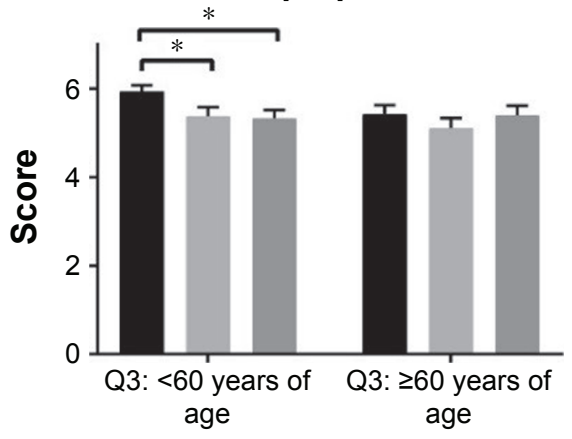

Confidence to have inhaled the entire dose
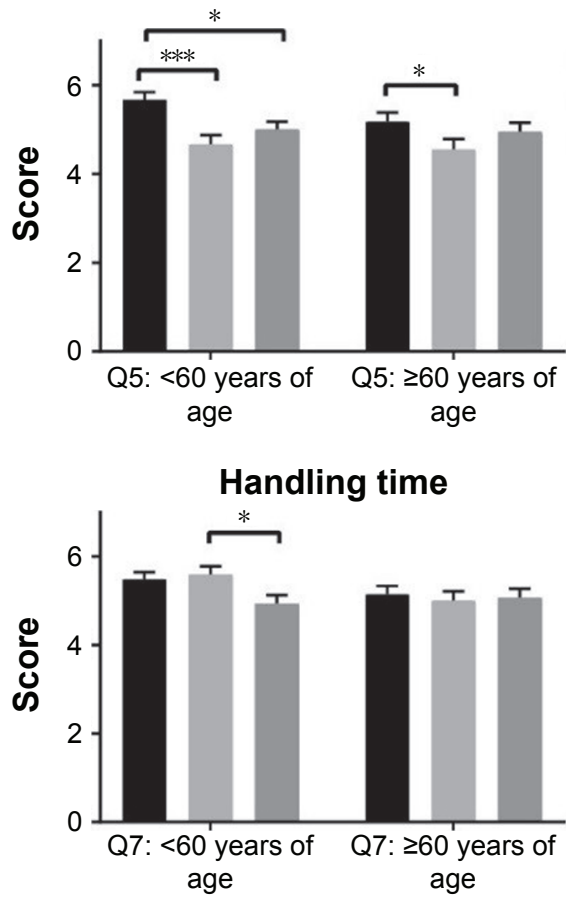

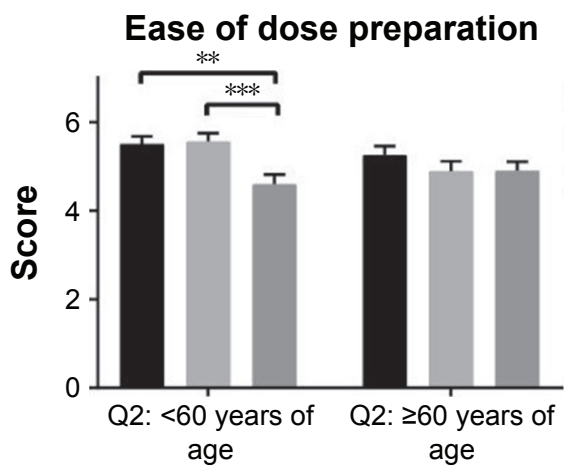

Clarity to indicate correct inhalation

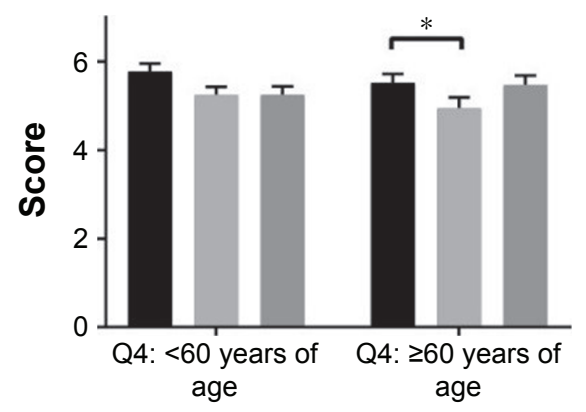

Ease of operation
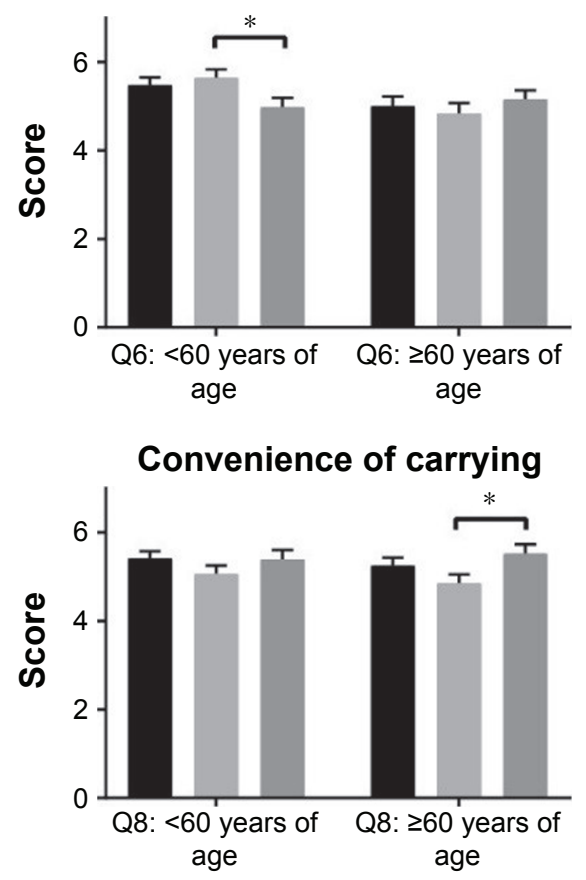

- Genuair $^{\circledR} \quad \square$ Ellipta $^{\mathrm{TM}} \square$ Breezhaler $^{\mathrm{TM}}$

Figure S2 Satisfaction scores on different attributes of the three DPIs as evaluated by subjects below 60 years of age or above or equal to 60 years of age. Notes: Mean values are plotted and the error bars represent the SEM. $*_{p} \leq 0.05 ;{ }^{* *} p \leq 0.01 ; * * * p \leq 0.00$ I.

Abbreviations: DPIs, dry powder inhalers; SEM, standard error of the mean. 
Satisfaction scores given by male and female subjects
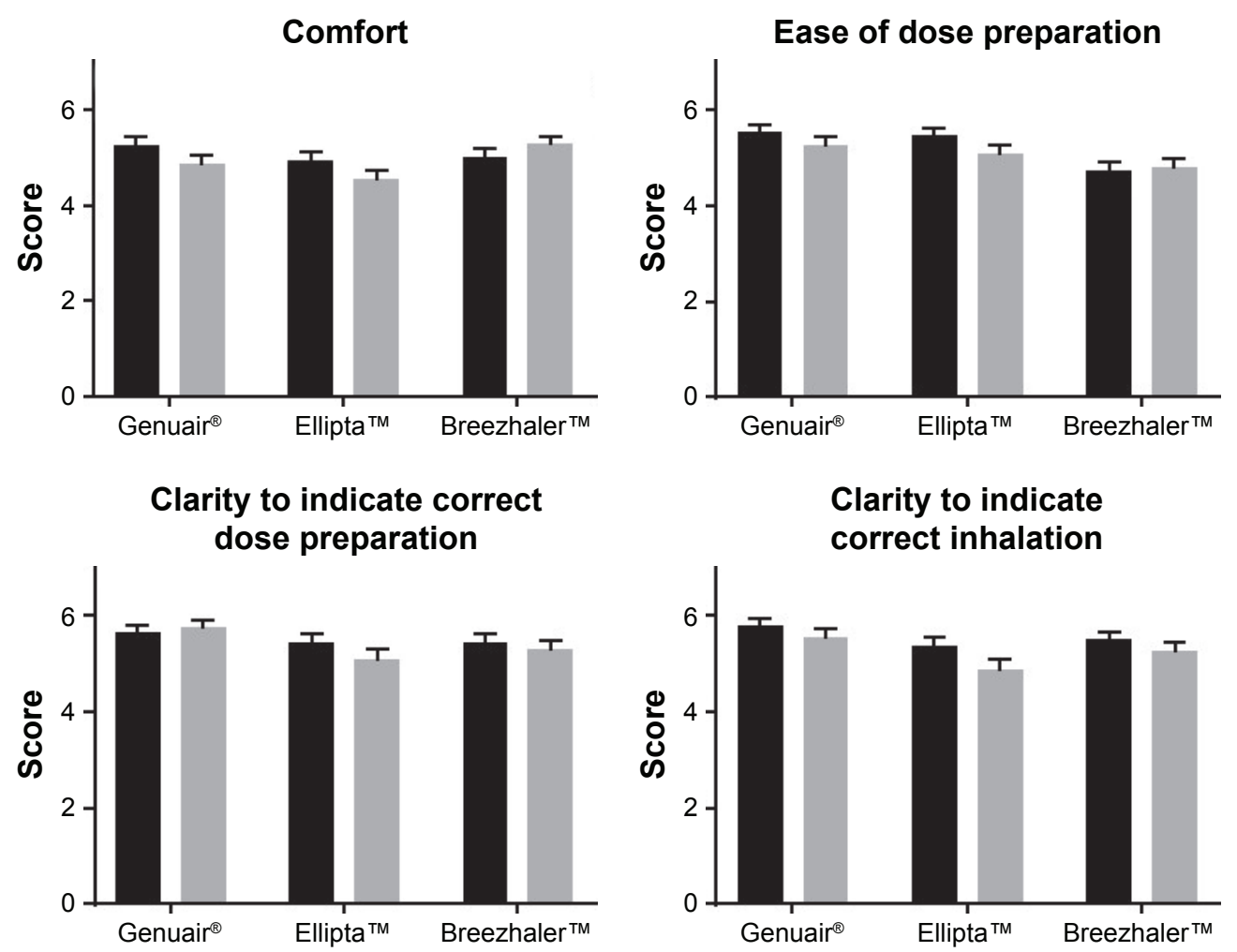

Confidence to have inhaled the entire dose
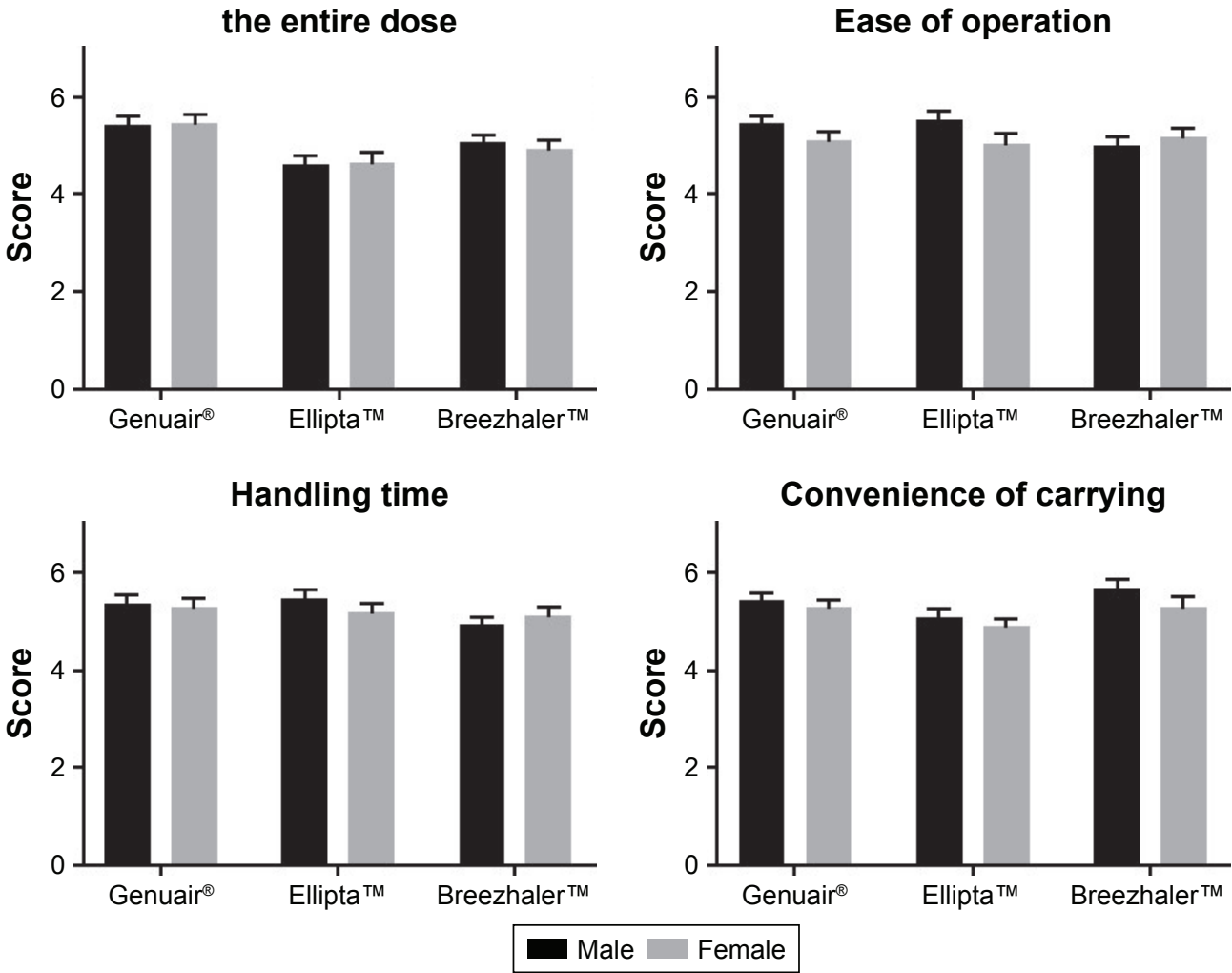

Figure S3 Satisfaction scores on different attributes of the three DPIs by male and female subjects.

Notes: Mean values are plotted and the error bars represent the SEM. No significance was detected.

Abbreviations: DPIs, dry powder inhalers; SEM, standard error of the mean. 
Satisfaction scores given by subjects $<60$ or $\geq 60$ years of age
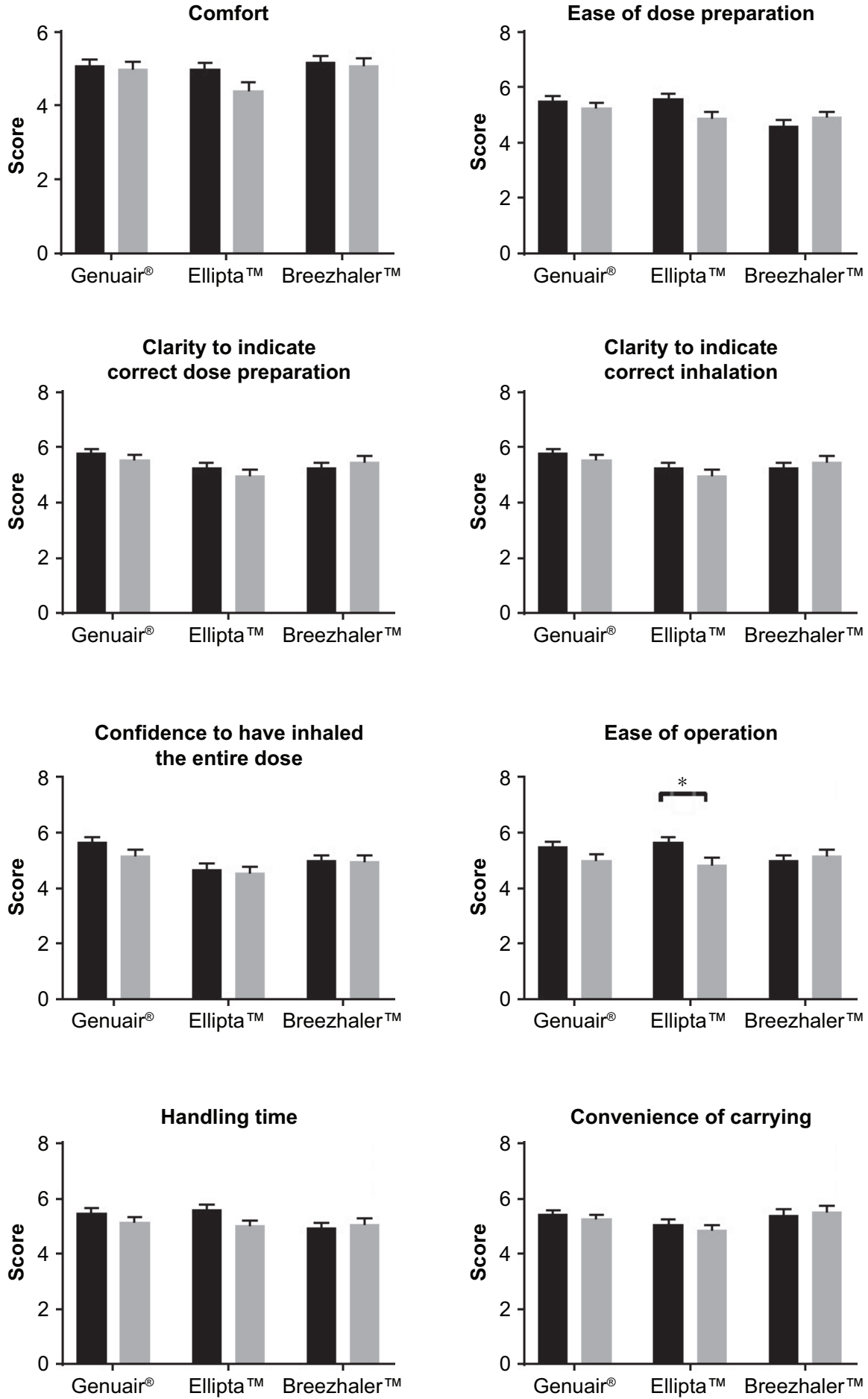

— $<0$ years of age

$\geq 60$ years of age

Figure S4 Satisfaction scores on different attributes of the three DPls by subjects $<60$ and $\geq 60$ years of age.

Notes: Mean values are plotted and the error bars represent the SEM. ${ }^{*} p \leq 0.05$.

Abbreviations: DPIs, dry powder inhalers; SEM, standard error of the mean. 
Table S2 0.2 SD and 0.5 SD of satisfactory scores of the three DPIs

\begin{tabular}{|c|c|c|c|c|c|c|}
\hline \multirow[t]{2}{*}{ Attribute } & \multicolumn{2}{|c|}{ Genuair $^{\circledR}$} & \multicolumn{2}{|c|}{ Ellipta $^{\mathrm{TM}}$} & \multicolumn{2}{|c|}{ Breezhaler ${ }^{\mathrm{TM}}$} \\
\hline & $0.2 \mathrm{SD}$ & 0.5 SD & $0.2 \mathrm{SD}$ & 0.5 SD & $0.2 \mathrm{SD}$ & $0.5 \mathrm{SD}$ \\
\hline Comfort & 0.315 & 0.787 & 0.331 & 0.827 & 0.302 & 0.756 \\
\hline Ease of dose preparation & 0.304 & $0.76 \mathrm{I}$ & 0.338 & 0.844 & 0.340 & 0.850 \\
\hline Clarity to indicate correct dose preparation & 0.275 & 0.687 & 0.349 & 0.872 & 0.325 & 0.812 \\
\hline Clarity to indicate correct inhalation & 0.297 & 0.744 & 0.331 & 0.827 & 0.314 & 0.785 \\
\hline Confidence to have inhaled the entire dose & 0.303 & 0.757 & 0.349 & 0.872 & 0.305 & 0.764 \\
\hline Ease of operation & 0.317 & 0.793 & 0.347 & 0.868 & 0.326 & 0.815 \\
\hline Handling time & 0.289 & 0.723 & 0.319 & 0.797 & 0.315 & 0.787 \\
\hline Convenience of carrying & 0.265 & 0.663 & 0.310 & 0.776 & 0.338 & 0.845 \\
\hline Overall satisfaction score & 3.870 & 9.674 & 4.434 & II.084 & 4.893 & $|2.23|$ \\
\hline
\end{tabular}

Abbreviation: DPIs, dry powder inhalers.

Table S3 Total number of non-critical errors committed during use of the three DPls

\begin{tabular}{lll}
\hline DPIs & $\begin{array}{l}\text { After reading } \\
\text { the instructions }\end{array}$ & $\begin{array}{c}\text { After visual demonstration } \\
\text { with verbal instructions }\end{array}$ \\
\hline Genuair $^{\circledR}$ & 280 & 112 \\
Ellipta $^{\text {TM }}$ & 299 & 127 \\
Breezhaler $^{\text {TM }}$ & 272 & 120 \\
\hline
\end{tabular}

Abbreviation: DPIs, dry powder inhalers.

\section{Publish your work in this journal}

The International Journal of COPD is an international, peer-reviewed journal of therapeutics and pharmacology focusing on concise rapid reporting of clinical studies and reviews in COPD. Special focus is given to the pathophysiological processes underlying the disease, intervention programs, patient focused education, and self management protocols.

\section{Dovepress}

This journal is indexed on PubMed Central, MedLine and CAS. The manuscript management system is completely online and includes a very quick and fair peer-review system, which is all easy to use. Visit http://www.dovepress.com/testimonials.php to read real quotes from published authors. 